\title{
PENGARUH MODEL PEMBELAJARAN LEARNING CYCLE 5E TERHADAP HASIL BELAJAR MATEMATIKA
}

\author{
Heri Nugroho'), ${ }^{1)}$ Sutriyono ${ }^{2)}$ \\ ${ }^{1,2)}$ Pendidikan Matematika FKIP Universitas Kristen Satya Wacana \\ ${ }^{1}$ E-mail: 202014024@student.uksw.edu
}

\begin{abstract}
ABSTRAK
Penelitian ini bertujuan untuk mengetahui ada tidaknya pengaruh model pembelajaran Learning Cycle 5E terhadap hasil belajar matematika pada materi teorema Pythagoras. Populasi dalam penelitian ini adalah siswa kelas VIII SMP Negeri 2 Tuntang. Pengambilan sampel dilakukan dengan teknik Cluster Random Sampling dan diperoleh siswa kelas VIIIE sebagai kelas eksperimen dan VIIIG sebagai kelas kontrol.Uji beda rerata kemampuan awal siswa dengan menggunakan uji Mann-Whitneymenghasilkan nilai signifikansi 0,851 (lebih dari 0,05), artinya kondisi awal kedua kelas seimbang. Hasil uji beda rata-ratamengahasilkan nilai signifikansi sebesar 0,024 (kurang dari 0,05). Hal ini berarti terdapat perbedaan yang signifikan antara rerata kedua kelas, maka disimpulkan terdapat pengaruh model pembelajaran Learning Cycle 5E terhadap hasil belajar matematika bagi siswa kelas VIII SMP Negeri 2 Tuntang.
\end{abstract}

Kata Kunci: Learning Cycle 5E, Hasil Belajar

\section{PENDAHULUAN}

Matematika merupakan ilmu universal yang mendasari perkembangan teknologi modern, mempunyai peran penting dalam berbagai disiplin ilmu dan memajukan daya pikir manusia (Winarsih, 2014).Hal ini yang mendasari matematika menjadi salah satu mata pelajaran penting yang harus dipelajari oleh setiap siswa dalam berbagai jenjang pendidikan, mulai dari taman kanak-kanak (TK) hingga perguruan tinggi. Tujuan diberikannya matematika pada semua jenjang pendidikan adalah untuk mempersiapkan siswa agar dapat menggunakan matematika dan pola pikir matematika dalam kehidupan sehari-hari dan dalam mempelajari ilmu pengetahuan lainnya (Thakarina, 2014). Mengingat pentingnya matematika, peningkatan mutu pendidikan matematika harus selalu diusahakan agar mutu pendidikan matematika makin baik (Sugarno, 2012).Salah satu upaya untuk meningkatkan mutu pendidikan di sekolah adalah dengan cara melalui perbaikan proses pembelajaran di sekolah (Handayani, 2011).

Dalam proses pembelajaran selama ini, seorang guru menjadi satu-satunya sumber info dan siswa hanya mendengarkan tanpa ikut aktif dalam kegiatan belajar mengajar (Handayani, 2011). Hal tersebut yang membuat hasil belajar siswa belum maksimal. Seorang guru harus mampu menetapkan, memilih dan menerapkan suatu model pembelajaran secara tepat sehingga mampu memecahkan permasalahan 
pembelajaran yang ada dan akhirnya dapat mencapai kompetensi atau tujuan pembelajaran secara optimal (Junaidah, 2012).Ketercapaian tujuan pembelajaran matematika dapat dilihat dari hasil belajar matematika (Apriana, 2016). Hasil belajar matematika adalah hasil yang dicapai siswa dari mempelajari tingkat penguasaan ilmu pengetahuan tertentu dengan alat ukur berupa evaluasi yang dinyatakan dalam bentuk angka, huruf, atau simbol (Winarsih, 2014).

Hal tersebut sesuai dengan kondisi yang terdapat di SMP Negeri 2 Tuntang. berdasarkan observasi yang peneliti lakukan, guru menjadi satu-satunya sumber belajar saat proses kegiatan belajar mengajar berlangsung. Siswa cenderung pasif, malu-malu untuk bertanya, malas untuk mengerjakan latihan soal dan kebanyakan dari siswa kurang bersemangat dalam pembelajaran matematika. Melalui model pembelajaran, seorang guru dapat merancang dan mengarahkan proses pembelajaran yang bermakna bagi siswa (Handayani, 2011). Oleh karena itu, peneliti menerapkan model pembelajaran Learning Cycle $5 E$ untuk mengatasi permasalahan tersebut.

Beberapa penelitian menyatakan bahwa model pembelajaran Learning Cycle 5E berpengaruh terhadap hasil belajar matematika. Misalnya penelitian yang dilakukan oleh Junaidah (2012) pada siswa kelas VII Madrasah Tsanawiyah Bahrul 'Ulum Al-Islamy Kecamatan Perhentian Raja Kabupaten Kampar, Setiawan (2017) pada siswa kelas V SD semester genap Tahun Pelajaran 2016/2017 di Gugus VII Kecamatan Buleleng Kabupaten Buleleng, dan Winarsih (2014) pada siswa kelas VII SMP Pangudi Luhur Salatiga Semester Genap Tahun Pelajaran 2013/2014. Ketiga penelitian ini menyatakan bahwa model pembelajaran Learning Cycle $5 E$ berpengaruh terhadap hasil belajar matematika.

Model pembelajaran Learning Cycle 5E, didalamnya siswa mengembangkan pemahaman konsep secara langsung dan bertahap (Thakarina, 2014). Setiap tahap yang terstruktur dalam Learning Cycle $5 E$ memiliki manfaat yang positif bagi siswa karena mengindikasikan pembelajaran yang bersifat student-centered (Sugarno, 2012). Model pembelajaran ini merupakan model pembelajaran yang mudah digunakan oleh guru dan dapat memberikan kesempatan untuk mengembangkan kreativitas belajar pada setiap siswa (Lestari, 2015). Adapaun tahapan model pembelajaran Learning Cycle 5Emeliputi:(1) tahap enggagement yaitu pada tahap ini guru membangun minat belajar, rasa keingintahuan terhadap materi yang akan dipelajari melalui guru mengajukan beberapa pertanyaan atau pernyataan kepada siswa, dan siswa membuat prediksi-prediksi yang nantinya akan dibuktikan pada tahap exploration;(2) tahap exploration yaitu dimana 
siswa mengeksplor segala pengetahuannya, siswa membuktikan prediksi-prediksi yang sudah dibuat pada tahap enggagement bersama kelompok belajar;(3) tahap elaboration yaitu tahap dimana siswa dituntut untuk mempertanggungjawabkan bukti dari prediksi bersama kelompoknya, menjelaskan bukti yang sudah dibuat bersama kelompoknya;(4) tahap explanation yaitu tahap dimana siswa diberikan situasi baru untuk memperluas konsep (5) tahap evaluation yaitu tahap dimana siswa menguji seberapa jauh konsep yang sudah didapat dari belajar individu dan belajar kelompok (Winarsih, 2014).

Berdasarkan uraian di atas maka rumusan masalah pada penelitian ini sebagai berikut: “Apakah terdapat pengaruh model pembelajaran Learning Cycle 5E terhadap hasil belajar matematika bagi siswa kelas VIII SMP Negeri 2 Tuntang?"

Dengan demikian penelitian ini bertujuan untuk mengetahui ada tidaknya pengaruh model pembelajaran Learning Cycle $5 E$ terhadap hasil belajar matematika bagi siswa kelas VIII SMP Negeri 2 Tuntang.

\section{METODE PENELITIAN}

Jenis penelitian ini adalah penelitianquasi eksperimen. Penelitian ini dilaksanakan di SMP Negeri 2 Tuntang pada semester II Tahun Pelajaran 2017/2018. Populasi dalam penelitian ini adalah seluruh siswa kelas VIII SMP Negeri 2 Tuntang Tahun Pelajaran 2017/2018. Pengambilan sampel dalam penelitian ini menggunakan teknik cluster random sampling dan diperoleh dua kelompok sampel yaitu kelas VIIIE (29 siswa) sebagai kelas eksperimen yang diajar dengan model pembelajaran Learning Cycle $5 E$ dan kelas VIIIG (29 siswa) sebagai kelas kontrol yang diajar dengan model pembelajaran konvensional. Variabel penelitian terdiri dari variabel bebas yaitu model pembelajaran Learning Cycle $5 E$ yang merupakan suatu model pembelajaran yang berpusat pada siswa, didesain sedemikian rupa sehingga siswa dapat mencapai kompetensi dasar dengan baik melalui beberapa tahapan dan variabel terikat yaitu hasil belajar matematika yang merupakan skor yang dapat dicapai untuk siswa dalam mata pembelajaran matematika pada materi teorema Pythagoras dan dapat diketahui dari skor tes yang telah dilakukan siswa.

Desain penelitian yang digunakan dalam penelitian ini adalah The Randomized Control Group Pretest-Posttest. Teknik pengumpulan data dalam penelitian ini dilakukan dengan cara dokumentasi dan tes. Metode dokumentasi digunakan untuk memperoleh nilai Ulangan Akhir Semester I siswa kelas VIII SMP Negeri 2 Tuntang Tahun Pelajaran 2017/2018 yang dijadikan nilai pretest untuk dasar uji keseimbangan kondisi awal siswa 
sebelum diberi perlakuan (treatment) dan data nilai posttest. Tes akhir (posttest) dilakukan setelah diberikan perlakuan (treatment) baik untuk kelas eksperimen maupun kelas kontrol. Posttestyang digunakan dalam penelitian ini adalah tes berbentuk objektif atau pilihan ganda. Kisi-kisi instrumen posttestdapat dilihat pada Tabel 1.

Tabel 1. Kisi-kisi instrumen posttest

\begin{tabular}{|c|c|c|}
\hline Materi & Indikator Soal & Nomor Soal \\
\hline \multirow{4}{*}{$\begin{array}{l}\text { Teorema } \\
\text { Pythagoras }\end{array}$} & $\begin{array}{l}\text { Menentukan rumus teorema Pythagoras jika } \\
\text { diketahui unsur-unsur dalam segitiga. }\end{array}$ & $1,6,7,12,17$ \\
\hline & $\begin{array}{l}\text { Menggunakan teorema Pythagoras untuk } \\
\text { menyelesaikan permasalahan yang berkaitan } \\
\text { dengan segitiga siku-siku. }\end{array}$ & $2,3,8,15,18$ \\
\hline & $\begin{array}{l}\text { Menentukan bilangan yang merupakan tripel } \\
\text { Pythagoras. }\end{array}$ & $4,9,10,13,14$ \\
\hline & $\begin{array}{l}\text { Menggunakan teorema Pythagoras } \\
\text { menyelesaikan masalah sehari-hari. }\end{array}$ & $5,11,16,19,20$ \\
\hline
\end{tabular}

Sumber: Data Primer, Tahun: 2018

Sebelum instrumen posttest digunakan dilakukan uji instrumen terlebih dahulu. Pengujian instrumen pada penelitian ini menggunakan pendapat para ahli (expert judgement) yang dilakukan oleh 1 dosen pembimbing dan 1 guru matematika. Kedua validator menyatakan bahwa instrumen layak digunakan. Hipotesis dalam penelitian ini adalah terdapat pengaruh model pembelajaran Learning Cycle $5 E$ terhadap hasil belajar matematika siswa kelas VIII SMP Negeri 2 Tuntang. Analisis terdiri dari dua jenis yaitu analisis deskriptif dan analisis inferensial. Analisis deskriptif digunakan untuk mengetahui nilai maksimum, minimum, rata-rata, dan standar deviasi sedangkan analisis inferensial meliputi uji normailitas, uji homogenitas, dan uji beda rerata.

Hipotesis penelitian diuji dengan uji rata-rata atau uji t Independent-Samples TTest yang sebelumnya telah dilakukan uji normalitas dan uji homogenitas. Uji normalitas bertujuan untuk mengetahui apakah data yang terkumpul berdistribusi normal atau tidak sedangkan uji homogenitas dimaksudkan untuk menguji bahwa setiap kelompok yang akan dibandingkan memiliki variansi yang sama (Thakarina, 2014). Jika homogen maka menggunakan Independent-Samples T-Test dengan tipe equal variances assummed dan jika tidak homogen maka menggunakan Independent-Sample T-Test dengan tipe equal variances not assumed (Susanti, 2016). Analisis uji beda rata-rata dilakukan jika kedua populasi berdistribusi normal dan homogen, ketika populasi tidak berdistribusi normal uji yang digunakan adalah uji beda rata-rata nonparametrik yaitu uji Mann-Whitney 
(Mandau, 2014). Keseluruhan uji yang dilakukan pada taraf sifgnifikansi sebesar 5\% dengan alat bantu perhitungan softwareIBM SPSS Statistics 20.

\section{HASIL DAN PEMBAHASAN}

\section{A. Hasil Penelitian}

\section{Kondisi Kemampuan Awal}

Data kondisi awal siswa diperoleh dari nilai Ulangan Akhir Semester (UAS) matematika siswa Semester I Tahun SMP Negeri 2 Tuntang Tahun Pelajaran 2017/2018. Nilai UAS matematika digunakan untuk nilai pretest dan mendeskripsikan objek yang diteliti melalui data sampel. Hasil analisis deskriptif kondisi awal siswa disajikan pada Tabel 2.

Tabel 2. Deskripsi Kondisi Awal

\begin{tabular}{llrrrr}
\hline \multicolumn{1}{c}{ Kelas } & N & \multicolumn{1}{c}{ Minimun } & \multicolumn{1}{c}{ Maximum } & Mean & Std. Deviation \\
\hline Eksperimen & 29 & 30 & 68 & 50,17 & 8,502 \\
Kontrol & 29 & 40 & 65 & 50,14 & 7,396 \\
Valid N (listwise) & 29 & & & & \\
\hline
\end{tabular}

Sumber: Data Primer, Tahun: 2018

Berdasarkan pada Tabel 2, pada kelas eksperimen nilai maksimun (68), rata-rata $(50,17)$, dan standar deviasi $(8,502)$ lebih tinggi dibandingkan nilai maksimun $(65)$, ratarata $(50,14)$, dan standar deviasi $(7,396)$ dari kelas kontrol sedangkan nilai minimun kelas kontrol (40) lebih tinggi dibandingkan kelas eksperimen (30). Hai ini menunjukkan bahwa jika dilihat dari nilai maksimum, rata-rata, dan standar deviasi siswa kelas eksperimen lebih baik dari siswa kelas kontrol. Hasil pretest dibagi menjadi 3 kategori yaitu tinggi, sedang, dan rendah. Pengkategorian hasil pretest disajikan pada Tabel 3.

Tabel 3. Pengkategorian Hasil Pretest

\begin{tabular}{ccccccc}
\hline \multirow{2}{*}{ No. } & \multirow{2}{*}{ Kategori } & \multirow{2}{*}{ Interval } & \multicolumn{2}{c}{ Kelas Eksperimen } & \multicolumn{2}{c}{ Kelas Kontrol } \\
\cline { 3 - 7 } & & & Jumlah & Presentase & Jumlah & Presentase \\
\hline 1. & Tinggi & $56 \leq$ nilai $<69$ & 6 & $20,68 \%$ & 6 & $20,68 \%$ \\
2. & Sedang & $43 \leq$ nilai $<56$ & 21 & $72,41 \%$ & 21 & $72,41 \%$ \\
3. & Rendah & $30 \leq$ nilai $<43$ & 2 & $6,89 \%$ & 2 & $6,89 \%$ \\
\hline
\end{tabular}

Sumber: Data Primer, Tahun: 2018

Tabel 3 menunjukkan bahwa kondisi awal, baik kelas eksperimen maupun kelas kontrol memiliki jumlah siswa yang sama dalam kategori tinggi (6 siswa), sedang (21 siswa), dan rendah (2 siswa). 
Uji normalitas kondisi awal dari kelas eksperimen dan kelas kontrol dilakukan sebelum pelaksanaan penelitian. Hasil analisis yang dilakukan dengan metode ShapiroWilk karena jumlah siswa pada kelas eksperimen dan kelas kontrol kurang dari 30 siswa. Hasil uji normalitas kondisi disajikan pada Tabel 4.

Tabel 4. Uji Normalitas Kondisi Awal

\begin{tabular}{lrrrrrrr}
\hline \multirow{2}{*}{ Kelas } & \multicolumn{3}{c}{ Kolmogorov-Smirnov $^{\mathbf{a}}$} & \multicolumn{3}{c}{ Shapiro-Wilk } \\
\cline { 2 - 8 } & \multicolumn{2}{c}{ Statistic } & \multicolumn{1}{c}{ df } & Sig. & Statistic & df & Sig. \\
\hline Eksperimen & 0,187 & 29 & 0,011 & 0,946 & 29 & 0,143 \\
Kontrol & & 0,205 & 29 & 0,003 & 0,912 & 29 & 0,020 \\
\hline Surnyyyyyy
\end{tabular}

Sumber: Data Primer, Tahun: 2018

Tabel 4 menunjukkan bahwa kelas eksperimen memiliki nilai signifikansi 0,143 dan kelas kontrol memiliki nilai signifikansi 0,020. Nilai signifikansi kelas kontrol kurang dari 0,05 sehingga dapat disimpulkan bahwa kedua kelas tidak berasal dari populasi yang berdistribusi normal sehingga uji beda rerata yang digunakan menggunakan uji Mann-Whitney. Uji Mann-Whitney dapat dilakukan setelah melakukan transformasi data dari data interval ke data ordinal. Hasil Uji Mann-Whitney disajikan pada Tabel 5 .

Tabel 5. Hasil Uji Mann-Whitney

\begin{tabular}{lr}
\hline & Peringkat \\
\hline Mann-Whitney U & 408,500 \\
Wilcoxon W & 843,500 \\
Z & $-0,188$ \\
Asymp. Sig. (2-tailed) & 0,851 \\
\hline
\end{tabular}

Sumber: Data Primer, Tahun: 2018

Tabel 5 menunjukkan nilai signifikansi sebesar 0,851 (lebih dari 0,05) yang artinya perbedaan rerata antara kelas eksperimen dan kelas kontrol tidak signifikan. Hai ini berarti kondisi awal kelas eksperimen dan kelas kontrol memiliki kemampuan awal yang seimbang. Setelah dilakukan pretest, selanjutnya adalah pelaksanaan pembelajaran selama 3 kali pertemuan $(3 \times 2$ jam pelajaran). Pembelajaran pada kelas VIIIE (Eksperimen) menggunakan model pembelajaran Learning Cycle 5E sedangkan kelas VIIIG (kontrol) menggunakan model konvensional. Setelah pelaksanaan pembelajaran, kedua kelas diberi tes (posttest). 


\section{Kondisi Kemampuan Akhir}

Kondisi kemampuan akhir siswa diambil dari data posttest. Materi yang digunakan dalam posttest mencakup materi teorema Pythagoras yang terdiri dari 20 soal pilihan ganda. Hasil dari nilai posttest kelas eksperimen dan kelas kontrol disajikan pada Tabel 6.

Tabel 6. Deskripsi Kondisi Akhir

\begin{tabular}{llrrrr}
\hline \multicolumn{1}{c}{ Kelas } & N & Minimun & Maximum & Mean & Std. Deviation \\
\hline Eksperimen & 29 & 55 & 100 & 74,83 & 11,988 \\
Kontrol & 29 & 55 & 90 & 68,28 & 9,285 \\
Valid N (listwise) & 29 & & & & \\
\hline
\end{tabular}

Sumber: Data Primer, Tahun: 2018

Berdasarkan pada Tabel 6, pada kelas eksperimen nilai maksimun (100), rata-rata $(74,83)$, dan standar deviasi $(11,988)$ lebih tinggi dibandingkan nilai maksimun $(90)$, ratarata $(68,28)$, dan standar deviasi $(9,285)$ dari kelas kontrol sedangkan nilai minimun $(55)$ kedua kelas adalah sama. Hai ini menunjukkan bahwa jika dilihat dari nilai maksimum, rata-rata, dan standar deviasi siswa kelas eksperimen lebih baik dari siswa kelas kontrol. Hasil posttest dibagi menjadi 3 kategori yaitu tinggi, sedang, dan rendah. Pengkategorian hasil posttest disajikan pada Tabel 7.

Tabel 7. Pengkategorian Hasil Posttest

\begin{tabular}{ccccccc}
\hline \multirow{2}{*}{ No. } & \multirow{2}{*}{ Kategori } & \multirow{2}{*}{ Interval } & \multicolumn{2}{c}{ Kelas Eksperimen } & \multicolumn{2}{c}{ Kelas Kontrol } \\
\cline { 3 - 6 } & & Jumlah & Presentase & Jumlah & Presentase \\
\hline 1. & Tinggi & $85 \leq$ nilai $\leq 100$ & 6 & $20,68 \%$ & 3 & $10,34 \%$ \\
2. & Sedang & $70 \leq$ nilai $<85$ & 16 & $55,17 \%$ & 10 & $34,48 \%$ \\
3. & Rendah & $55 \leq$ nilai $<70$ & 7 & $24,13 \%$ & 16 & $55,17 \%$ \\
\hline
\end{tabular}

Sumber: Data Primer, Tahun: 2018

Berdasarkan Tabel 7, sebagian besar siswa kelas eksperimen masuk kategori sedang $(55,17 \%)$ dan kelas kontrol masuk kategori rendah $(55,17)$. Persentase siswa kelas eksperimen pada kategori tinggi (20,68\%) lebih baik dari persentase kategori tinggi $(10,34 \%)$ kelas kontrol.

Uji normalitas kondisi akhir dari kelas eksperimen dan kelas kontrol dilakukan setelah pelaksanaan penelitian. Hasil analisis yang dilakukan dengan metode ShapiroWilk karena jumlah siswa pada kelas eksperimen dan kelas kontrol kurang dari 30 siswa. Hasil uji normalitas kondisi kemampuan akhir disajikan pada Tabel 8. 
Tabel 8. Uji Normalitas Kondisi Akhir

\begin{tabular}{lccccccc}
\hline \multirow{2}{*}{ Kelas } & \multicolumn{3}{c}{ Kolmogorov-Smirnov $^{\text {a }}$} & \multicolumn{3}{c}{ Shapiro-Wilk } \\
\cline { 2 - 8 } & \multicolumn{2}{c}{ Statistic } & df & Sig. & Statistic & df & Sig. \\
\hline Eksperimen & 0,184 & 29 & 0,013 & 0,937 & 29 & 0,086 \\
Kontrol & 0,190 & 29 & 0,009 & 0,933 & 29 & 0,065 \\
\hline
\end{tabular}

Sumber: Data Primer, Tahun: 2018

Tabel 8 menunjukkan nilai signifikansi hasil uji normalitas kelas eksperimen sebesar 0,086 dan kelas kontrol sebesar 0,065. Kedua nilai signifiansi lebih dari 0,05 artinya kedua kelas berasal dari populasi yang berdistribusi normal. Uji selanjutnya yang digunakan adalah uji homogenitas. Uji homogenitas menggunakan Levene Statistic. Hasil uji homogenitas disajikan pada Tabel 9.

Tabel 9. Hasil Uji Homogenitas

\begin{tabular}{rrrr}
\hline LeveneStatistic & df1 & df2 & sig. \\
\hline 0,616 & 1 & 56 & 0,436 \\
\hline
\end{tabular}

Sumber: Data Primer, Tahun: 2018

Hasil uji homogenitas pada Tabel 9 menunjukkan nilai signifikansi sebesar 0,436 (lebih dari 0,05) sehingga disimpulkan kedua kelas berasal dari populasi dengan variansi yang sama (homogen). Setelah memenuhi syarat normalitas dan homogenitas maka dilakukan uji beda rerata dengan menggunakan uji Independent-Samples $T$ Test tipe Equal variances assumed. Hasil uji Independent-Samples T Test disajikan pada Tabel 10.

Tabel 10. Hasil Uji Independent-Samples T Test t-test for Equality of Means

\begin{tabular}{|c|c|c|c|c|c|c|c|}
\hline & \multirow[t]{2}{*}{$\mathbf{t}$} & \multirow[t]{2}{*}{ df } & \multirow[t]{2}{*}{$\begin{array}{l}\text { Sig. (2- } \\
\text { tailed) }\end{array}$} & \multirow[t]{2}{*}{$\begin{array}{c}\text { Mean } \\
\text { Difference }\end{array}$} & \multirow[t]{2}{*}{$\begin{array}{l}\text { Std. Error } \\
\text { Difference }\end{array}$} & \multicolumn{2}{|c|}{$\begin{array}{l}95 \% \text { Confidence } \\
\text { Interval of the } \\
\text { Difference }\end{array}$} \\
\hline & & & & & & Lower & Upper \\
\hline $\begin{array}{l}\text { Equal } \\
\text { variances } \\
\text { assumed }\end{array}$ & 2,327 & 56 & 0,024 & 6,552 & 2,816 & 0,911 & 12,192 \\
\hline $\begin{array}{l}\text { Equal } \\
\text { variances } \\
\text { not } \\
\text { assumed }\end{array}$ & 2,327 & 52,703 & 0,024 & 6,552 & 2,816 & 0,903 & 12,200 \\
\hline
\end{tabular}

Sumber: Data Primer, Tahun: 2018

Tabel 10 menunjukkan nilai Sig. (2-tailed) sebesar 0,024 lebih kecil dari 0,05. Hal ini berarti kondisi kemampuan akhir kedua kelas memiliki perbedaan rata-rata yang 
signifikan. Oleh karena itu dapat disimpulkan bahwa terdapat pengaruh model pembelajaran Learning Cycle 5E terhadap hasil belajar matematika siswa kelas VIII SMP Negeri 2 Tuntang. Hasil tersebut sesuai dengan hipotesis pada penelitian ini.

\section{B. Pembahasan}

Tujuan penelitian ini adalah untuk mengetahui ada tidaknya pengaruh model pembelajaran Learning Cycle 5E terhadap hasil belajar matematika bagi siswa kelas VIII SMP Negeri 2 Tuntang. Hasil belajar sangat dipengaruhi oleh pelaksanaan pembelajaran, sehingga diperlukan analisis pelaksanaan berdasarkan lembar observasi untuk menjelaskan tingkat keberhasilan pembelajaran. Hasil keterlaksanaan pembelajaran dengan model pembelajaran Learning Cycle 5E dapat dilihat pada Tabel 11. Pada tabel tersebut tampak bahwa peneliti telah melakukan pembelajaran dengan model pembelajaran Learning Cycle $5 E$ dengan kategori sangat baik.

Tabel 11. Keterlaksanaan Pembelajaran dengan Model Pembelajaran Learning Cycle 5E

\begin{tabular}{lccccccc}
\hline \multirow{2}{*}{ Aspek yang Diamati } & \multicolumn{4}{c}{ Persentase } & \multirow{2}{*}{ Kategori } & \multirow{2}{*}{ Simpulan } \\
\cline { 2 - 5 } & I & II & III & Rata-rata & & \\
\hline A. Kegiatan Pendahuluan & 80 & 85 & 90 & 85 & SB & \multirow{2}{*}{ Sangat } \\
B. Kegiatan Inti & 79 & 79 & 87 & 81 & SB & Baik \\
C. Kegiatan Penutup & 81 & 75 & 87 & 81 & SB & \\
\hline
\end{tabular}

Sumber: Data Primer, Tahun: 2018

Selain observasi keterlaksanaan pembelajaran, dilakukan juga pengamatan terhadap aktivitas siswa. Hasil pengamatan dapat dilihat pada Tabel 12. Hasil pengamatan terhadap siswa, hanya kehadiran siswa yang masuk dalam kategori sangat baik.

Tabel 12. Aktivitas Siswa dengan Model Pembelajaran Learning Cycle 5E

\begin{tabular}{llcccccc}
\hline \multirow{2}{*}{ Aspek yang Diamati } & \multicolumn{4}{c}{ Persentase } & \multirow{2}{*}{ Kategori } & \multirow{2}{*}{ Simpulan } \\
\cline { 2 - 5 } & I & II & III & Rata-rata & & \\
\hline A. Kehadiran & 96 & 86 & 96 & 92 & SB & \\
B. Kedisiplinan & 78 & 70 & 81 & 76 & B & \\
C. Keaktifan & 71 & 69 & 76 & 72 & B & Baik \\
D. & Perhatian & 71 & 68 & 75 & 71 & B & \\
E. Tanggung Jawab & 65 & 67 & 76 & 69 & B & \\
\hline
\end{tabular}

Sumber: Data Primer, Tahun: 2018

Kelas kontrol diberikan perlakukan dengan model pembelajaran konvensional. Pemberian materi dan informasi berasal dari guru, siswa cenderung pasif, kurang antusias, dan kurang bersemangat dalam mengikuti pembelajaran matematika. Rata-rata nilai kelas kontrol adalah 68,28. Rata-rata nilai kelas kontrol lebih rendah dibandingkan 
dengan rata-rata kelas eksperimen. Kondisi kelas seperti itu yang membuat hasil belajar matematika kelas kontrol menjadi kurang memuaskan.

Perlakuan berbeda diberikan pada kelas eksperimen dengan menggunakan model pembelajaran Learning Cycle 5E. Berdasarkan aktivitas siswa dengan model pembelajaran Learning Cycle 5E, siswa mulai aktif, tidak malu untuk bertanya, tidak malas untuk mengerjakan latihan soal, dan sangat bersemangat ketika mengikuti pembelajaran matematika. Hal ini sesuai dengan penelitian yang dilakukan oleh Winarsih (2014), siswa tampak antusias dalam belajar, seperti 1) rasa keingintahuannya tampak yang ditunjukkan dengan rasa penasaran terhadap pokok bahasan, yang sebelumnya siswa tampak kurang bersemangat dalam pembelajaran matematika; 2) siswa berlatih untuk memecahkan sesuatu permasalahan dan berlatih bertanggungjawab atas pekerjaannya, yang sebelumnya siswa hanya duduk menerima konsep baru; 3) siswa berlatih bertanggungjawab dan percaya diri dalam mempresentasikan hasil pekerjaannya, yang sebelumnya siswa masih malu-malu dan ragu; 4) siswa mencoba memecahkan suatu hal baru yang ditunjukkan dengan sikap siswa yang antusias dalam memecahkan suatu pemecahan masalah yang bertujuan untuk meluaskan konsep, yang sebelumnya siswa hanya malas jika dihadapkan dengan suatu pemecahan masalah; 5) siswa antusias bertanya terhadap konsep yang sudah didapat siswa, yang sebelumnya siswa malu untuk bertanya. Rata-rata nilai kelas eksperimen adalah 74,83.

Berdasarkan deskripsi data kondisi akhir siswa kelas VIII SMP Negeri 2 Tuntang menunjukkan bahwa siswa yang mengikuti pembelajaran dengan model pembelajaran Learning Cycle $5 E$ memiliki hasil yang lebih tinggi dibanding dengan siswa yang mengikuti pembelajaran dengan model pembelajaran konvensional. Terdapat beberapa faktor yang dapat menjadikan model pembelajaran Learning Cycle $5 E$ lebih baik dari pada model pembelajaran konvensional antara lain adalah model pembelajaran Learning Cycle $5 E$ menuntut siswa untuk berpartisipasi secara aktif dan siswa bukan lagi sebagai pendengar. Hal ini sesuai dengan yang disampaikan oleh Setiawan (2017), model pembelajaran konvensional pemberian informasi dan materi dari guru, sehingga pembelajaran berpusat pada guru yang dapat menyebabkan siswa menjadi pasif dalam mengikuti proses pembelajaran. Hal itulah yang menyebabkan hasil belajar matematika siswa yang mengikuti pembelajaran dengan model pembelajaran konvensional lebih rendah dibandingkan dengan siswa yang mengikuti pembelajaran dengan model pembelajaran Learning Cycle $5 E$. 
Disisi lain dalam pembelajaran Learning Cycle $5 E$ terdapat kesulitan yang dialami siswa yaitu pada tahap elaboration. Tahap elaboration yaitu tahap dimana siswa dituntut untuk mempertanggungjawabkan bukti dari prediksi bersama kelompoknya dan menjelaskan bukti yang sudah dibuat bersama kelompoknya. Pelaksanaan pada tahap ini, siswa telah mampu memberikan penjelasan dan jawaban yang lebih baik dibandingkan dengan pemberian pertanyaan pada tahap engagement, meskipun masih ada beberapa siswa masih belum terbiasa mengungkapkan pendapatnya di depan kelas. Oleh sebab itu, guru memberikan apresiasi berupa tepuk tangan, pujian, atau nilai tambah bagi siswa yang sudah mau menjawab pertanyaan dari guru. Hal ini dilakukan agar siswa lebih berani mengungkapkan pendapatnya.

Pemberian perlakuan yang berbeda antara kedua kelas ternyata diperoleh hasil yang berbeda. Perbedaan rata-rata hasil tes kelas eksperimen dengan kelas kontrol sebesar 6,55 dan hasil statistik perbedaan hasil belajar matematika berbeda secara signifikansi berdasarkan uji $\mathrm{t}$ sebesar 2,327 dengan signifikansi $0,024<0,05$ maka rataan kedua kelompok berbeda secara signifikan.

Hasil penelitian ini sejalan dengan penelitian yang dilakukan sebelumsebelumnya, seperti penelitian yang dilakukan oleh Junaidah (2012), menyatakan bahwa penggunaan model pembelajaran Learning Cycle 5E berpengaruh terhadap hasil belajar matematika siswa kelas VII MTs Bahrul 'Ulum Tahun Ajaran 2011/2012 pada pokok bahasan segi empat dan Winarsih (2014) menyatakan bahwa model Learning Cycle berpengaruh terhadap hasil belajar matematika pada materi bangun datar siswa kelas VII SMP Pangudi Luhur Salatiga Semester Genap Tahun Pelajaran 2013/2014.

\section{KESIMPULAN}

\section{A. Kesimpulan}

Berdasarkan hasil penelitian dan pembahasan, rata-rata kelas yang menggunakan model pembelajaran Learning Cycle 5E $(74,83)$ lebih tinggi dari hasil belajar matematika siswa yang menggunakan model pembelajaran konvensional $(68,28)$. Perbedaan rata-rata hasil tes kelas eksperimen dengan kelas kontrol sebesar 6,55.

Hasil statistik perbedaan hasil belajar matematika berbeda secara signifikansi berdasarkan uji $\mathrm{t}$ sebesar 2,327 dengan signifikansi $0,024<0,05$ maka rataan kedua kelompok berbeda secara signifikan. Jadi, dapat disimpulkan bahwa terdapat pengaruh model pembelajaran Learning Cycle $5 E$ terhadap hasil belajar matematika bagi siswa kelas VIII SMP Negeri 2 Tuntang. 


\section{B. Saran}

Berdasarkan hasil penelitian, peneliti menyanmpaikan saran sebagai berikut:

1. Pembelajaran degan model pembelajaran Learning Cycle $5 E$ dapat dijadikan sebagai alternatif model pembelajaran bagi guru dalam rangka menambah variasi model pembelajaran.

2. Hasil penelitian ini dapat memberikan data empirik. Oleh karena itu, bagi peneliti lain yang ingin menerapkan model pembelajaran Learning Cycle 5E untuk menerapkan pada materi lain dan mengembangkan kemampuan matematika lainnya karena peneliti lakukan hanya mencakup hasil belajar. 


\section{DAFTAR PUSTAKA}

Apriana, S. A. (2015). Penerapan Model Learning Cycle 5E (LC 5E) untuk Meningkatkan Hasil Belajar Matematika Siswa Kelas X8 SMA Negeri 2 Siak Hulu. Jurnal Online Mahasiswa (JOM) Bidang Keguruan dan Ilmu Pendidikan,2(2), 1-9.

Handayani, S. D. (2011). Pengembangan Perangkat Pembelajaran Matematika dengan Model Learning Cycle-5E Pada Pokok Bahasan Kesebangunan Kelas IX SMP Negeri Benjeng. http://digilib.uinsby.ac.id/9342/. Diakses pada tanggal 31 Januari 2018.

Junaidah. (2012). Pengaruh Penggunaan Model Pembelajaran Learning Cycle 5 Fase (Lc 5E) Terhadap Hasil Belajar Matematika Siswa Kelas VII Madrasah Tsanawiyah Bahrul 'Ulum Al-Islamy Kecamatan Perhentian Raja Kabupaten Kampar. http://repository.uin-suska.ac.id/2738/. Diakses pada tanggal 31 Januari 2018.

Lestari, E. C. (2015). Penerapan Model Pembelajaran Learning Cycle 5E dengan Metode Pemberian Tugas dan Resitasi untuk Meningkatkan Aktivitas dan Hasil Belajar Matematika pada Pokok Bahasan Aritmetika Sosial Siswa Kelas VII A Semester Genap SMP Negeri 10 Jember Tahun Ajaran 2013/2014. Kadikma, 6(2), 83-94.

Mandau, L. S. 2014. Pengaruh Metode Problem Based Learning (PBI) Terhadap Motivasi Belajar dan Hasil Belajar Siswa Kelas VIII SMP Negeri 1 Pamona Utara Sulawesi Tengah.http://repository.uksw.edu/handle/123456789/5603. Diakses pada tanggal 31 Januari 2018.

Setiawan, I. W. P. 2017. Pengaruh Model Pembelajaran Learning Cycle 5E Berbantuan Mind Mapping Terhadap Hasil Belajar Matematika. Mimbar PGSD Undiksha, 5(2), 1-11.

Sugarno, S. H. 2013. Upaya Peningkatan Hasil Belajar Matematika dan Motivasi Siswa Kelas V dengan Model Pembelajaran Bersiklus (Learning Cycle) SD 1 Karangbener Kecamatan Bae Kabupaten Kudus Semesteri Tahun 2012/2013. 
http://repository.uksw.edu/handle/123456789/7773. Diakses pada tanggal 31 Januari 2018.

Susanti, S. 2016. Pengaruh Model Pembelajaran Learning Cycle 7E Terhadap Kemampuan Pemecahan Masalah Matematika bagi Siswa Kelas X MIA SMA Kristen Satya Wacana Salatiga. http://repository.uksw.edu/handle/123456789/9826. Diakses pada tanggal 3 Februari 2018.

Thakarina, I. 2014. Pengaruh Model Pembelajaran Learning Cycle "5e" Terhadap Keaktifan Belajar dan Hasil Belajar Siswa Kelas IX SMP Negeri 3 Getasan Semester I Tahun Ajaran 2014/2015. Jurnal. http://repository.uksw.edu/handle/123456789/5637. Diakses pada tanggal 31 Januari 2018.

Winarsih, W. 2014. Pengaruh Model Learning Cycle terhadap Hasil Belajar Matematika pada Materi Bangun Datar Siswa Kelas VII SMP Pangudi Luhur Salatiga Semester Genap Tahun Pelajaran 2013/2014. http://repository.uksw.edu/handle/123456789/4975. Diakses pada tanggal 31 Januari 2018. 